\section{Cureus}

\title{
Biochemistry in Endeavor Adventure Racers Study (BEARS)
}

\author{
Matthew Wetschler ${ }^{1}$, David Radler ${ }^{1}$, Mark Christensen ${ }^{1}$, Sean Rundell ${ }^{2}$, Grant Lipman ${ }^{1}$ \\ 1. School of Medicine, Stanford University 2. Department of Rehabilitation Medicine, University of \\ Washington
}

$\square$ Corresponding author: Matthew Wetschler, matthew.wetschler@gmail.com Disclosures can be found in Additional Information at the end of the article

\section{Abstract}

Background: Adventure sports events consist of a combination of two or more endurance disciplines, such as orienteering, running, and rock climbing, that range from a day's to a week's duration. No studies have examined acute kidney injury (AKI) in adventure sports athletes.

Objectives: To describe the prevalence of AKI in participants in the Endeavor Team Challenge, a 30-hour, 40-mile adventure race.

Methods: In this prospective observational study, body weights were recorded at race registration. At the finish line, blood sample results by point-of-care testing and weights were recorded. Changes in serum creatinine $(\mathrm{Cr})$ from an estimated baseline value and severity of AKI were calculated, with "risk of injury" defined as $1.5 \mathrm{x}$ baseline $\mathrm{Cr}$, and "injury" defined as 2 $\mathrm{x}$ baseline Cr. These two categories of AKI were combined to calculate the total prevalence.

Results: There were 88 enrolled study participants with complete data available on 46 (52\%). The mean age of those enrolled in the study was 36.8 years (+/- 7.7), 90\% were males, and body mass index (BMI) was $25.7 \mathrm{~kg} / \mathrm{m}^{2}$ (+/- 2.4). Of the competitors who completed the study, 34 (73\%) had some degree of AKI, with 27 (58\%) found to be at "risk" and seven (15\%) with "injury". There was a significant correlation between weight loss and elevated $\mathrm{Cr}(\mathrm{r}=-0.29, \mathrm{p}=0.047)$, with a trend towards nonsteroidal anti-inflammatory drug (NSAID) use being correlated with AKI $(\mathrm{p}=0.058)$.

Conclusion: Acute kidney injury was observed in the majority of the Endeavor Team Challenge adventure racers, similar to what has been observed in multistage ultramarathons, and greater than after standard marathons and single-stage ultramarathons.

Received 07/08/2016

Review began $07 / 12 / 2016$ Review ended 01/20/2017 Published 02/11/2017

\section{(c) Copyright 2017}

Wetschler et al. This is an open access article distributed under the terms of the Creative Commons Attribution License CC-BY 3.0., which permits unrestricted use, distribution, and reproduction in any medium, provided the original author and source are credited.
Categories: Emergency Medicine

Keywords: wilderness medicine, acute kidney injury, adventure athletes

\section{Introduction}

Adventure sports are growing in popularity in the United States and around the world with an exponential growth of both participants and events [1]. These events consist of a combination of two or more endurance disciplines, such as orienteering, running, and rock climbing, that may range from a day's to a week's duration. The distance usually exceeds the marathon distance of 26.2 miles, placing it in the ultra-endurance category. The Endeavor Team Challenge (ETC) 2014 is a representative event, including over 30 hours of activity and 
involving more than 40 miles of walking or running interspersed with a variety of other challenges, such as climbing, kayaking, and obstacle courses.

The presence of acute kidney injury (AKI) in athletes is a well-researched topic in multiple populations: healthy marathon race finishers [2-3], marathon racers seeking medical care [4-5], and ultramarathon race participants [6-7]. Renal dysfunction during endurance events is thought to be due to a multifactorial combination of dehydration, injury from muscle breakdown, heat stress, and the use of non-steroidal anti-inflammatory drugs (NSAIDs), although acute renal failure is rare in this population [8]. No studies have examined AKI in adventure racers as a novel group of athletes.

The ETC is a unique athletic endeavor; though still predominantly a running event, various other activities are distributed throughout the race, providing continuous activity but not of a single discipline. The interspersed activities between long stretches of running in the ETC may provide an opportunity for normalization of biochemical changes, similar to the pattern observed in running-exclusive multistaged events [6] or following single-day ultramarathons $[3,9]$. Alternatively, the multidisciplinary nature of the event may further compound renal dysfunction. The purpose of this study is to determine the prevalence of AKI in adventure racers.

\section{Materials And Methods}

\section{Setting and participants}

The Endeavor Team Challenge 2014 took place in Bear Creek, California in the Stanislaus National Forest. It was a 30-hour multidisciplinary event that spanned more than 40 miles and was divided into four subcomponents: a 20-mile march with a weighted pack; a five-event portion involving multiple challenges that included rock climbing, strength tests, rappelling, and obstacle courses; a night navigation portion with waypoint finding (approximately six hours duration), and concluding with a 12-mile run without a pack with a boating component of two miles. All competitors were given an opportunity to enroll in the study during race registration. Institutional approval was obtained from the Stanford University School of Medicine Institutional Review Board (\#30928).

\section{Procedures}

The racers were enrolled during race registration the night prior to the race at which time a written informed consent was obtained. Racer demographics, including sex, age, height, weight, and BMI, were recorded. Blood samples were obtained from each participant at the completion of the race. Blood samples were obtained by lancet and blood capillary collection tubes and then immediately measured onsite using an iSTAT point-of-care analyzer (Abbott, East Windsor, NJ).

\section{Analysis}

A descriptive analysis was performed of racer demographics and the prevalence of AKI at the end of the event. Baseline glomerular filtration rate (GFR) was assumed to be $100 \mathrm{~mL} / \mathrm{min}$ when a racer's age was less than or equal to 40 years, and 140 minus years of age when participants were older than 40 years [10]. This estimated GFR was then used to calculate a baseline pre-race serum creatinine (Cr) using the "modification of diet in renal disease" (MDRD) equation [11] of $\mathrm{GFR}=186 \mathrm{x}(\mathrm{Cr})^{-1.154} \mathrm{x}$ (age in years) $)^{-0.203} \mathrm{x}(0.742$ if female $) \times(1.210$ if African American). The modified MDRD was used because it is the current formula recommended by the National Kidney Foundation for estimation of renal function [11]. Changes in $\mathrm{Cr}$ from an estimated baseline and prevalence of AKI were determined with "risk" of injury defined as $1.5 \mathrm{x}$ baseline 
$\mathrm{Cr}$, and "injury" defined as $2 \mathrm{x}$ baseline $\mathrm{Cr}$; these two categories of severity were combined to calculate the total prevalence of AKI [12]. The analysis was performed combining all final measured values as a single cohort regardless of whether the participant completed or withdrew from the race. Paired t-test and Wilcoxon signed rank tests were used for analysis; statistical significance was considered to be $p<0.05$. All analysis was by the Statistical Package for Social Sciences (SPSS), version 19.0 (IBM SPSS Statistics, Armonk, NY).

\section{Results}

Of the 88 enrolled participants, complete data were available on 46 (52\%). Baseline characteristics of all participants are in Table 1. Comparison between those who completed the study and the $48 \%$ lost to follow-up showed statistically significant differences in age, BMI, and history of completed marathons. Those who completed the study were, on average, older, had a lower BMI, and had run more marathons. Seventy-four percent of study participants encountered some severity of AKI (Table 2). There was a significant correlation between weight loss and elevated $\mathrm{Cr}(\mathrm{r}=-0.29, \mathrm{p}=0.047)$, although this was not seen in racers who demonstrated AKI $(p=0.19)$. There was a trend towards a significant association between NSAID use and racers with AKI (without AKI $=250 \mathrm{mg}+/-173$; with AKI $=374 \mathrm{mg}+/-581$ ), although this did not obtain statistical significance $(\mathrm{p}=0.058)$. Differences between those with and without AKI were not statistically significant in regards to percent weight change $(0.71 \mathrm{~kg}$, $95 \% \mathrm{CI}-0.36$ to $1.78, \mathrm{p}=0.19)$ or blood urea nitrogen $(\mathrm{BUN}) / \mathrm{Cr}(3.05,95 \% \mathrm{CI}-0.87$ to $6.97, \mathrm{p}=$ $0.12)$ 


\section{Cureus}

\begin{tabular}{|c|c|c|c|c|c|c|c|}
\hline \multirow[t]{2}{*}{ Variable } & \multicolumn{2}{|c|}{ All $(n=88)$} & \multicolumn{2}{|c|}{$\begin{array}{l}\text { Completers } \\
(n=46)\end{array}$} & \multicolumn{2}{|c|}{$\begin{array}{l}\text { Lost to Follow Up } \\
(n=42)\end{array}$} & \multirow{2}{*}{$\begin{array}{l}\text { Comparison of Completers vs Lost to } \\
\text { Follow-up } \\
\text { P-value }\end{array}$} \\
\hline & Mean & SD & Mean & SD & Mean & SD & \\
\hline Age & 36.8 & 7.7 & 39 & 7.5 & 34.4 & 7.3 & $<0.01$ \\
\hline Male (n, \%) & 79 & 89.8 & 42 & 91.3 & 37 & 88.1 & 0.62 \\
\hline Height (meters) & 1.8 & 0.1 & 1.8 & 0.1 & 1.8 & 0.1 & 0.28 \\
\hline Pre-weight & 82.6 & 11.3 & 81.2 & 9 & 84.1 & 13.3 & 0.24 \\
\hline BMI & 25.7 & 2.4 & 25.1 & 2.3 & 26.4 & 2.4 & 0.02 \\
\hline Marathons (n, \%) & & & & & & & $<0.01$ \\
\hline 0 & 48 & 55.2 & 19 & 41.3 & 29 & 70.7 & \\
\hline 1 & 18 & 20.7 & 15 & 32.6 & 3 & 7.3 & \\
\hline $2+$ & 21 & 24.1 & 12 & 26.1 & 9 & 22 & \\
\hline $\begin{array}{l}\text { Ultramarathons (n, } \\
\%)\end{array}$ & & & & & & & 0.657 \\
\hline 0 & 69 & 79.3 & 35 & 76.1 & 34 & 82.9 & \\
\hline 1 & 9 & 10.3 & 6 & 13 & 3 & 7.3 & \\
\hline $2+$ & 9 & 10.3 & 5 & 10.9 & 4 & 9.8 & \\
\hline NSAID use (n, \%) & 14 & 15.9 & 8 & 17.4 & 6 & 14.3 & 0.93 \\
\hline $\begin{array}{l}\text { Estimated } \\
\text { baseline } \mathrm{Cr}\end{array}$ & 0.76 & 0.09 & 0.77 & 0.08 & 0.76 & 0.09 & 0.92 \\
\hline
\end{tabular}

\section{TABLE 1: Baseline Characteristics}

BMI: body mass index; NSAID: non-steroidal anti-inflammatory; Cr: creatinine; SD: standard deviation 


\section{Cureus}

\begin{tabular}{|c|c|c|c|c|c|c|}
\hline \multirow[b]{2}{*}{ Variable } & \multicolumn{2}{|c|}{ Normal $(n=12)$} & \multicolumn{2}{|c|}{ At Risk ( $\mathbf{n}=27)$} & \multicolumn{2}{|c|}{ Injury (n=7) } \\
\hline & Mean & SD & Mean & SD & Mean & SD \\
\hline Age & 41.2 & 8.7 & 37.5 & 6.9 & 41.1 & 7.3 \\
\hline Male (n \%) & 12 & $100 \%$ & 26 & $96 \%$ & 4 & $57 \%$ \\
\hline Height & 1.8 & 0.1 & 1.8 & 0.1 & 1.8 & 0.1 \\
\hline BMI & 24.4 & 2.6 & 25.4 & 2.2 & 25.5 & 2.3 \\
\hline Marathons & 1.9 & 2.4 & 2.0 & 3.6 & 2.6 & 5.5 \\
\hline Ultramarathons & 0.8 & 1.8 & 0.4 & 1.0 & 0.4 & 0.8 \\
\hline
\end{tabular}

\section{TABLE 2: Characteristics by Acute Kidney Injury (AKI) Status and Severity}

BMI: body mass index; SD: standard deviation

\section{Discussion}

We noted a greater prevalence of AKI in this adventure race (74\%) compared to marathons (40\%) [13] and single-stage ultramarathons (34\%) [14] but similar to that seen in multistage ultramarathon runners (55-85\%) [6-7]. This suggests that continuous multidiscipline events with relatively short running sections can generate similar renal stress to that generated by purely running events. In prior studies of multistage running races, a pattern of near-complete recovery was seen between days of racing [6]. Future studies may define how much rest is required to achieve renal function recovery between intra-race events. All women study participants were categorized in the "injury" or "risk" groups, though the small numbers of female participants $(n=4)$ limited any statistical inference. Previously, the most commonly reported medical complaints in adventure races were skin and soft tissue injuries [15]. This is in contrast to single-day obstacle races that show more trauma and unique injury patterns [16]. While the occurrence of clinically serious acute renal failure in this population is likely rare, awareness of the high incidence of subclinical AKI is valuable information for race participants.

The mechanism of AKI in our study population is likely multifactorial: a combination of over 30 hours of strenuous, multidiscipline activity rough wilderness terrain and dehydration, heat stress, NSAID use, and muscle tissue breakdown. Because weight loss (a proxy for dehydration) was significantly associated with elevated $\mathrm{Cr}$, we theorize that there is a pathophysiologic contribution of hypovolemia and subsequent decreased renal perfusion as the cause of AKI. This significant association has been previously observed in ultramarathons [7]. Our observed lack of significant association between NSAID use and development of AKI correlates with prior running-specific observational studies [7, 14].

As with all convenience sampling, there is a risk that a measured or unmeasured characteristic of study participants may vary from the overall group, introducing unmeasured bias or limiting the study's generalizability to a broader population.

We calculated baseline creatinine rather than using direct measurement. This was done to maximize study participants and is common practice in studies similar to this because blood 
sampling significantly increases study attrition. The attrition in our study was $48 \%$, similar to prior work done in multistage ultramarathons [6]. We used weight gain or loss as a proxy for hydration status. Direct tracking of water intake would have been superior but was too logistically complex to ensure accurate completion.

Racers dropped out of the study for one of three reasons. They were either unable to complete the competition due to injury or lack of stamina, they refused to have blood sampled, or there was equipment malfunction. We were unable to quantify the reasons in the lost to follow-up group.

The Endeavor Team Challenge is a unique event, and although it is an example of an adventure race, there is significant heterogeneity within the adventure race domain. Observed trends during the ETC may be more or less apparent given the length, types of activity, and climate of other events.

\section{Conclusions}

Acute kidney injury was observed in the majority of Endeavor Team Challenge adventure racers, similar to that seen with multistage ultramarathons and greater than that seen with standard marathons and single-stage ultramarathons. Given that multistage endurance events are becoming more popular, studies to delineate how much time is required for adequate renal function recovery are needed and could potentially help race planning for optimal safety. Because of the high prevalence of NSAID use during endurance events, further studies are recommended to examine the impact of NSAIDs on renal function in the setting of multistage events.

\section{Additional Information \\ Disclosures}

Human subjects: Consent was obtained by all participants in this study. Stanford Institutional Review Board issued approval 30928. Animal subjects: All authors have confirmed that this study did not involve animal subjects or tissue. Conflicts of interest: In compliance with the ICMJE uniform disclosure form, all authors declare the following: Payment/services info: All authors have declared that no financial support was received from any organization for the submitted work. Financial relationships: All authors have declared that they have no financial relationships at present or within the previous three years with any organizations that might have an interest in the submitted work. Other relationships: All authors have declared that there are no other relationships or activities that could appear to have influenced the submitted work.

\section{References}

1. Greenberg MR, Kim PH, Duprey RT, Jayant DA, Steinweg BH, Preiss BR, Barr GC Jr: Unique obstacle race injuries at an extreme sports event: a case series. Ann Emerg Med. 2014, 63:36166. 10.1016/j.annemergmed.2013.10.008

2. Irving RA, Noakes TD, Burger SC, Myburgh KH, Querido D, van Zyl Smit R: Plasma volume and renal function during and after ultramarathon running. Med Sci Sports Exerc. 1990, 22:58187.

3. Page AJ, Reid SA, Speedy DB, Mulligan GP, Thompson J: Exercise-associated hyponatremia, renal function, and nonsteroidal antiinflammatory drug use in an ultraendurance mountain run. Clin J Sport Med. 2007, 17:43-48. 10.1097/JSM.0b013e31802b5be9

4. Irving RA, Noakes TD, Buck R, van Zyl Smit R, Raine E, Godlonton J, Norman RJ: Evaluation of renal function and fluid homeostasis during recovery from exercise-induced hyponatremia. J

Appl Physiol (1985). 1991, 70:342-48. 
5. Reid SA, King MJ: Serum biochemistry and morbidity among runners presenting for medical care after an Australian mountain ultramarathon. Clin J Sport Med. 2007, 17:307-10. 10.1097/JSM.0b013e31804c77da

6. Lipman GS, Krabak BJ, Waite BL, Logan SB, Menon A, Chan GK: A prospective cohort study of acute kidney injury in multi-stage ultramarathon runners: the Biochemistry in Endurance Runner Study (BIERS). Res Sports Med. 2014, 22:185-92. 10.1080/15438627.2014.881824

7. Lipman GS, Krabak BJ, Rundell SD, Shea KM, Badowski N, Little C: Incidence and prevalence of acute kidney injury during multistage ultramarathons. Clin J Sport Med. 2016, 26:314-19. 10.1097/JSM.0000000000000253

8. Clarkson PM: Exertional rhabdomyolysis and acute renal failure in marathon runners . Sports Med. 2007, 37:361-63. 10.2165/00007256-200737040-00022

9. Irving RA, Noakes TD, Raine RI, Van Zyl Smit R: Transient oliguria with renal tubular dysfunction after a $90 \mathrm{~km}$ running race. Sports Med. 1990, 22:756-61.

10. Granerus G, Aurell M: Reference values for 51Cr-EDTA clearance as a measure of glomerular filtration rate. Scand J Clin Lab Invest. 1981, 41:611-16. 10.3109/00365518109090505

11. Levey AS, Coresh J, Balk E, Kausz AT, Levin A, Steffes MW, Hogg RJ, Perrone RD, Lau J, Eknoyan G; National Kidney Foundation: National Kidney Foundation practice guidelines for chronic kidney disease: evaluation, classification, and stratification. Ann Intern Med. 2003, 139:137-47. 10.7326/0003-4819-139-2-200307150-00013

12. Lewington AJ, Sayed A: Acute kidney injury: how do we define it? . Ann Clin Biochem. 2009, 47:4-7. 10.1258/acb.2009.009249

13. McCullough PA, Chinnaiyan KM, Gallagher MJ, Colar JM, Geddes T, Gold JM, Trivax JE: Changes in renal markers and acute kidney injury after marathon running . Nephrology (Carlton). 2011, 16:194-99. 10.1111/j.1440-1797.2010.01354.x

14. Hoffman MD, Stuempfle KJ, Fogard K, Hew-Butler T, Winger J, Weiss RH: Urine dipstick analysis for identification of runners susceptible to acute kidney injury following an ultramarathon. J Sports Sci. 2013, 31:20-31. 10.1080/02640414.2012.720705

15. McLaughlin KA, Townes DA, Wedmore IS, Billingsley RT, Listrom CD, Iverson LD: Pattern of injury and illness during expedition-length adventure races. Wilderness Environ Med. 2006 , 17:158-61. 10.1580/PR29-05 